\title{
HUBUNGAN POSTUR KEPALA DENGAN TUMBUH KEMBANG MANDIBULA PADA PENDERITA OBSTRUKSI SALURAN NAPAS ATAS DENGAN KEBIASAAN BURUK NAPAS MULUT
}

\author{
Erliera $^{1, *}$, Miesje K $\mathbf{P}^{1, * *}$, Krisnawaty $^{2, * *}$ \\ * Peserta Pendidikan Dokter Gigi Spesialis Ortodonti Fakultas Kedokteran Gigi Universitas \\ Indonesia, Jl. Salemba Raya No. 4. Jakarta \\ ** Staf Pengajar Departemen Ortodonti Kedokteran Gigi Universitas Indonesia, Jl. Salemba Raya \\ No. 4. Jakarta
}

\section{Keywords:}

obstruction of the upper respiratory tract; Kifosis;

Mandible growth

\begin{abstract}
Objective: To investigate the correlations between head posture and mandible growth in Deuteromalayid OURT (obstruction of the upper respiratory tract) patients with mouth breathing habit. Material \& Methods: The study used cross sectional design for 64 subjects including 32 OURT patients with mouth breathing habit and 32 normal subjects, all 12 to 15 years old. Lateral cephalometry radiograph was taken for head posture measurements and mandibular growth (ramus height, mandibular length, and mandibular rotation) measurements. Results: The fraction of subjects with kifosis head posture in OURT with mouth breathing habit (34.4\%) was larger than that in normal subjects $(28.1 \%)$. There is no correlation between head posture and OURT with mouth breathing habit, but there is a correlation between OURT with mouth breathing habit and mandibular rotation. Conclusion: Patients with OURT and mouth breathing habit show more vertical growth of mandible than normal subjects.
\end{abstract}

\section{Pendahuluan}

Tumbuh kembang dentokraniofasial merupakan proses perubahan yang memiliki komponen-komponen morfogenik yang saling berhubungan dan seimbang antara jaringan lunak dengan jaringan keras. ${ }^{1}$ Pertumbuhan mandibula memiliki arah pertumbuhan ke depan dan bawah kemudian diikuti oleh pertumbuhan dari faring, lidah dan struktur lain yang berkaitan. ${ }^{1,2}$ Tumbuh kembang dentokrani ofasial bersifat multifaktorial seperti faktor genetik, umur, jenis kelamin, ras, kebiasaan buruk, adanya penyakit, nutrisi atau trauma. ${ }^{1,3,4}$ Proffit (2003) menyatakan bahwa, faktor genetik merupakan faktor dasar yang mempengaruhi tumbuh kembang dentokraniofa- 
sial. Waktu dan percepatan pertumbuhan dari seseorang terletak pada gen, dan kondisi akhir tumbuh kembang dentokraniofasial merupakan kombinasi antara gen dengan lingkungan. ${ }^{3}$ Ras merupakan salah satu faktor yang membedakan pertumbuhan dan perkembangan dentokraniofasial dan fisik seorang individu pada kelompok tertentu. $^{5}$

Hubungan OSNA dengan Kebiasaan Buruk Napas Mulut, Postur Kepala serta Tumbuh Kembang Mandibula

Obstruksi saluran napas atas (OSNA) adalah suatu keadaan tersumbatnya saluran pernapasan bagian atas rongga hidung sampai faring sehingga mengganggu proses pernapasan yang normal. ${ }^{6}$ Gejala umum penderita obstruksi saluran napas atas seperti, sesak dan tidak lega saat bernapas, berkurangnya sensasi penciuman, sering mengantuk hingga kehilangan kesadaran pada tahap yang parah (apnoea). ${ }^{7}$

Penderita obstruksi saluran napas atas biasanya mempunyai kebiasaan bernapas melalui mulut. ${ }^{3,8-10}$ Penderita yang bernapas melalui mulut memiliki karakteristik khas disebut dengan 'adenoid facies' yaitu, memiliki pertumbuhan vertikal berlebih dengan wajah yang dolikofasial, mulut yang membuka dan adanya kecendrungan memiliki maloklusi gigitan terbuka, bibir atas pendek dan lip incompetent, hidung dengan cuping (nostril) yang kecil, posisi lidah ke bawah, palatum yang dalam, pertumbuhan maksila berbentuk-V, dll. ${ }^{3,8-10}$

Banyak penelitian menyatakan bahwa individu yang bernapas melalui mulut menyebabkan postur kepala menjadi lebih mendongak (hiperekstensi) dengan sudut kranioservikal yang membesar. ${ }^{9,11,12}$ Selain OSNA, kontrol dari postur kepala dapat dipengaruhi oleh berbagai macam stimulus, seperti adanya anomali dari tulang belakang, jaringan keloid, komponen saraf., ${ }^{9,11,13}$ Adaptasi postur kepala seperti ini dalam jangka waktu panjang akan menimbulkan perubahan pada pertumbuhan dan perkembangan dentokraniofasial normal, terutama pertumbuhan dan perkembangan mandibula.

\section{Pemeriksaan Saluran Napas, Postur Kepala dan Tumbuh Kembang Mandibula}

Pemeriksaan saluran napas dapat diperiksa baik secara klinis juga maupun radiografi. Pemeriksaan klinis meliputi observasi sederhana dan pemeriksaan menggunakan alat seperti nasoendoskopi, rinoskopi, rhinomanometric atau acoustic-rhinometry. Pemeriksaan radiografi meliputi radiografi panoramik, sefalometri lateral dan antero-posterior, CTscan, MRI hingga 3D imaging. ${ }^{14,15}$

Pemeriksaan postur kepala dan tumbuh kembang mandibula menggunakan radiografi sefalometri lateral. Solow dan Tallgren menentukan tiga variabel analisis postur kepala yaitu, sudut cranio-cervical (NSL/OPT, NSL/CVT), sudut cervico-horizontal (OPT/HOR, CVT/HOR) dan sudut craniovertical (NSL/VER, NL/VER, Gambar 1A). ${ }^{12,16}$ Sudut cranio-cervical lebih menunjukkan adanya hubungan yang signifikan terhadap morfologi kraniofasial daripada sudut craniovertical. ${ }^{12}$ Banyak metode yang dapat digunakan untuk pengukuran morfologi dan tumbuh kembang mandibula, dapat disimpulkan menjadi empat pengukuran yaitu, tinggi mandibula, lebar mandibula, panjang mandibula serta rotasi mandibula. ${ }^{4,17,18}$

\section{Bahan dan Cara Kerja}


Penelitian berlangsung di Klinik THT RSCM FK-UI, Klinik Ortodonti dan Klinik Radiologi RSGMP FKG-UI, dari 86 subjek OSNA dengan kebiasaan buruk napas mulut diukur adalah sudut kranioservikal (sudut NSL/OPT, Gambar 1A). Variabel tumbuh kembang mandibula yang diukur meliputi tinggi ramus mandibula (pengukuran linier titik R3-

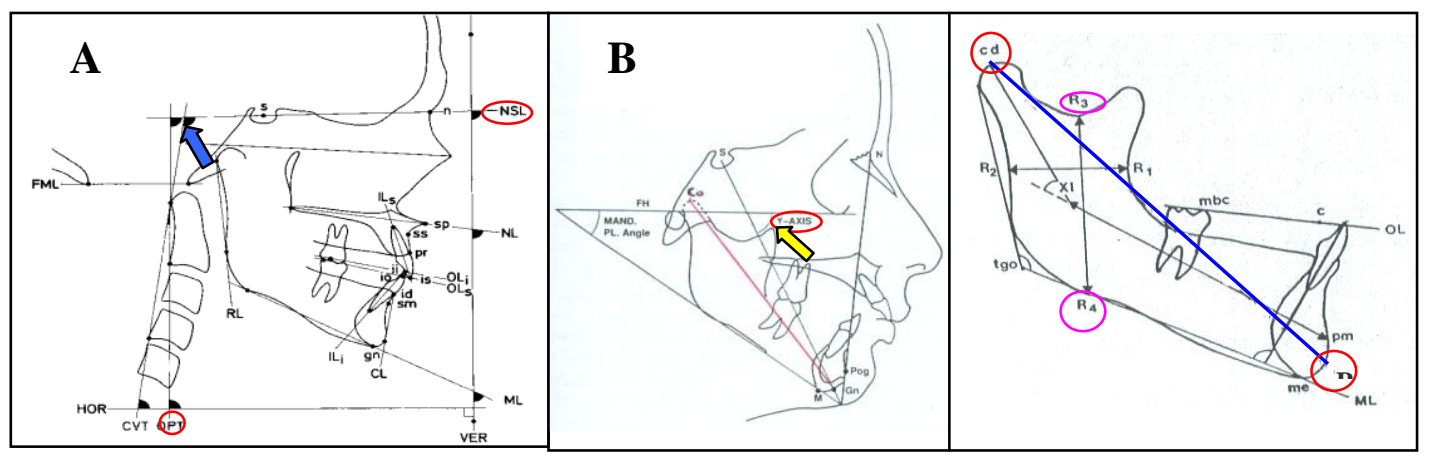

dipilih 32 subjek secara acak dan diperoleh 32 subjek normal, usia $12-15$ tahun ras Deutromalayid yang memenuhi kriteria inklusi dan eksklusi. Variabel postur kepala yang
R4), panjang mandibula (pengukuran linier titik $\mathrm{Co}-\mathrm{Po}$ ) dan pengukuran rotasi mandibula (sudut $Y$-axis) terlihat pada Gambar 1B.

Gambar 1. A. Pengukuran sudut postur kepala, cranio-cervical (NSL/OPT) B. Pengukuran tumbuh kembang mandibula (dikutip dari Solow dan Tallgren, Kerr, dkk dan Jacobson) $)^{18,15,16}$

Pada penelitian ini dilakukan uji keandalan intraoperator pada pengukuran postur kepala dan tumbuh kembang mandibula dengan pengambilan data yang dilakukan dua kali dalam rentang waktu satu minggu untuk subjek normal dan tiga hari untuk subjek OSNA dengan kebiasaan buruk napas mulut. Tidak ditemukan perbedaan bermakna antara pengukuran pertama dan kedua pada kedua kelompok subjek kecuali pada pengukuran variabel panjang mandibula pada subjek OSNA dengan kebiasaan buruk napas mulut.

\section{Hasil}

Sebaran subjek dan hasil uji perbedaan variabel postur kepala subjek OSNA dengan kebiasaan buruk napas mulut dan subjek normal terlihat pada Tabel 1. Dari hasil uji chi-square antara subjek OSNA dengan kebiasaan buruk napas mulut dengan subjek normal menunjukkan bahwa tidak terdapat perbedaan bermakna variabel postur kepala antara subjek OSNA dengan kebiasaan buruk napas mulut dengan subjek normal.

Tabel 1. Sebaran subjek dan hasil uji perbedaan variabel postur kepala subjek OSNA dengan kebiasaan buruk napas mulut dan subjek normal (Uji chi-square)

\begin{tabular}{|c|c|c|c|c|c|c|c|c|c|}
\hline & & \multirow{2}{*}{$\mathrm{N}$} & \multicolumn{6}{|c|}{ Sebaran Variabel Postur Kepala } & \multirow[t]{2}{*}{$\mathrm{p}$} \\
\hline & & & Lordosis & $(\%)$ & Normal & $(\%)$ & Kifosis & $(\%)$ & \\
\hline \multirow{3}{*}{$\begin{array}{c}\text { Kelompok } \\
\text { Sampel }\end{array}$} & Normal & 32 & 10 & 31,25 & 13 & 40,62 & 9 & 28,13 & \multirow{3}{*}{0,337} \\
\hline & & & & & & & & & \\
\hline & OSNA & 32 & 5 & 15,63 & 16 & 50 & 11 & 34,37 & \\
\hline
\end{tabular}

Nilai rerata dan simpangan baku variabel pada subjek OSNA dengan kebiasaan buruk postur kepala dan tumbuh kembang mandibula 
pada Tabel 2. Hanya variabel rotasi mandibula

antara kedua kelompok subjek.

yang menunjukkan adanya perbedaan bermakna

Erliera, Miesje K P, Krisnawaty

Tabel 2. Karakteristik dan Hasil Uji perbedaan Postur Kepala dan Tumbuh Kembang Mandibula subjek OSNA dengan kebiasaan buruk napas mulut dan subjek normal (Uji-t)

\begin{tabular}{|c|c|c|c|c|c|c|c|}
\hline & \multicolumn{3}{|c|}{ Subjek OSNA dengan Napas Mulut } & \multicolumn{3}{|c|}{ Subjek Normal } & \multirow[t]{2}{*}{$\begin{array}{c}p \\
(\mathrm{Uji}-\mathrm{t})\end{array}$} \\
\hline & $\mathrm{N}$ & Rerata & $\begin{array}{c}\text { Simpang } \\
\text { Baku }\end{array}$ & $\mathrm{N}$ & Rerata & Simpang Baku & \\
\hline Postur Kepala & & 99,71 & 8,12 & & 96,72 & 7,54 & 0,132 \\
\hline Tinggi Ramus & & 45,90 & 3,47 & & 46,67 & 4,51 & 0,446 \\
\hline $\begin{array}{l}\text { Panjang } \\
\text { Mandibula }\end{array}$ & 32 & 114,71 & 6,37 & 32 & 117,56 & 6,75 & 0,085 \\
\hline Rotasi Mandibula & & 64,30 & 2,86 & & 60,32 & 3,11 & $0,000^{*}$ \\
\hline
\end{tabular}

Pada Tabel 3 terlihat uji korelasi Somers'd antara variabel postur kepala dan OSNA dan pada Tabel 4 terlihat hasil uji korelasi Pearson's

antara variabel tumbuh kembang mandibula dengan variabel postur kepala.

Tabel 3. Hubungan antara Postur Kepala dengan OSNA Subjek yang Memiliki Kebiasaan Buruk Napas Mulut (Uji korelasi Somers'd)

\begin{tabular}{llccccc}
\hline & & \multicolumn{3}{c}{ Sebaran Variabel Postur Kepala } & \multirow{2}{*}{ P } & r (Sommers'd) \\
\cline { 3 - 5 } & & Lordosis & Normal & Kifosis & & \\
\hline Kelompok & Normal & 10 & 13 & 9 & \multirow{2}{*}{0,241} & 0,121 \\
Sampel & OSNA & 5 & 16 & 11 & & \\
\hline
\end{tabular}

Tabel 4. Hubungan antara Postur Kepala dengan Tumbuh Kembang Mandibula Subjek OSNA dengan kebiasaan buruk napas mulut (Uji korelasi Pearson's)

\begin{tabular}{lcc}
\hline & \multicolumn{2}{c}{ Postur Kepala } \\
\cline { 2 - 3 } & $\mathrm{P}$ & $\mathrm{r}$ (Pearson's) \\
\hline Tinggi Ramus & 0,599 & 0,097 \\
Panjang Mandibula & 0,752 & 0,058 \\
Rotasi Mandibula & 0,009 & $0,452^{*}$ \\
\hline $\mathbf{r}) \mathbf{0}, \mathbf{4 0}-\mathbf{0 , 5 9 9} \rightarrow \mathbf{s e d a n g}$ & &
\end{tabular}

Hasil uji korelasi Somers'd, tidak ditemukan hubungan antara variabel postur kepala dan OSNA dan hasil uji korelasi Pearson's, hanya pada variabel rotasi mandibula yang memiliki hubungan bermakna dengan postur kepala dengan kekuatan korelasi sedang.

Karakteristik Postur Kepala pada Subjek OSNA dengan Kebiasaan Buruk Napas Mulut dan pada Subjek Normal

Pada penelitian Solow, dkk dibuktikan bahwa terdapat hubungan yang searah antara terjadinya OSNA dengan postur kepala. ${ }^{10,11}$ Purwanegara menyatakan bahwa kebiasaan buruk napas mulut juga merupakan faktor risiko terjadinya penyimpang an terhadap postur

\section{Pembahasan}


kepala, dengan prevalensi sebesar $86,5 \%$ pada subjek OSNA dengan kebiasaan buruk napas mulut dan $13,5 \%$ pada subjek OSNA tanpa kebiasaan buruk napas mulut. ${ }^{19}$

Dalam penelitian ini, walaupun tidak dapat dibuktikan secara statistik, proporsi postur kepala dan nilai rerata antara kedua kelompok subjek tersebut tetap menunjukkan adanya perbedaan. Proporsi variabel postur kepala normal dan kifosis lebih besar terdapat pada subjek OSNA dengan kebiasaan buruk napas mulut dari kelompok subjek normal (Tabel 1), begitu juga nilai rerata sudut postur kepala pada subjek OSNA dengan napas mulut lebih besar dari subjek normal (Tabel 2).

Perbedaan nilai dengan penelitian terdahulu mungkin disebabkan oleh adanya perbedaan ras subjek yang diteliti. Ras Deutro-Malayid merupakan campuran antara ras Austromelanesoid dan Mongoloid. ${ }^{5}$ Glinka mengatakan bahwa ras Kaukasoid memiliki ciri khas kepala yang dolichocephaly dan lebar hidung yang sempit dibandingkan dengan ras Austromelanesoid dan Mongoloid yang memiliki ciri khas kepala yang lebih brachycephaly dengan rongga hidung yang sedang hingga lebar. ${ }^{1,5}$ Enlow dan Hans mengatakan bahwa kranium yang dolichocepha ly memiliki lebar antero-posterior faring yang besar dan sebaliknya pada kranium yang brachycephaly. ${ }^{1}$

Hal lain yang berpengaruh adalah faktor kebiasaan bernapas melalui mulut, umumnya subjek OSNA yang memiliki kebiasaan bernapas melalui mulut juga tetap bernapas melaui hidung (partial mouth breather). ${ }^{15}$ Dalam penelitian ini, subjek yang digunakan kurang banyak, kriteria inklusi subjek tidak melibatkan derajat keparahan terjadinya OSNA (seperti berapa besar adanya pembesaran adenoid atau hipertropi choncae) dan tidak melakukan pengukuran terhadap anatomi lebar dari rongga hidung sehingga hasil yang dicapai pada penelitian ini kurang akurat.

Karakteristik Tumbuh Kembang Mandibula pada Subjek OSNA dengan Kebiasaan Buruk Napas Mulut dan pada Subjek Normal
Tumbuh kembang kondil mandibula sangat mudah dipengaruhi oleh stimulasi mekanis (lingkungan) seperti adanya OSNA, karena tumbuh kembang kondil mandibula tidak berorigo pada pertumbuhan tulang kartilago primer pada basis kranium., ${ }^{9,10,2}$ OSNA biasanya dibarengi dengan kebiasaan buruk napas mulut, untuk memudahkan pernapasan, subjek OSNA akan menengadahkan kepalanya sehingga posisi mandibula dan lidah akan terletak lebih ke bawah, oleh karena itu pertumbuhan mandibula yang normalnya ke bawah dan ke depan akan memiliki kecenderungan pertumbuhan mandibula lebih vertikal (ke bawah dan ke belakang) sehingga memiliki penyimpangan dentokraniofasial dengan wajah yang hiperdivergen, memiliki maloklusi skeletal kelas II Angle dengan profil fasial yang cembung (adenoid facies). ${ }^{3,8-10,20}$ Penelitian ini juga membuktikan hal tersebut, pada variabel arah rotasi mandibula, nilai rerata variabel tersebut lebih besar pada subjek OSNA dengan kebiasaan buruk napas mulut dari subjek normal.

Opdebeeck, dkk menyatakan bahwa subjek dengan arah pertumbuhan mandibula searah jarum jam memiliki kecendrungan wajah yang dolichofacial dan memiliki tinggi ramus lebih pendek dari subjek normal atau pada subjek dengan wajah brachyfacial. ${ }^{17}$ Walaupun pada penelitian ini tidak terbukti secara statistik, terlihat adanya perbedaan nilai rerata antara kedua kelompok tersebut dengan nilai rerata tinggi ramus mandibula lebih kecil pada subjek OSNA dengan napas mulut dari subjek normal. Kecilnya tinggi ramus mandibula akan menyebabkan tinggi posterior wajah menjadi pendek dan rasio sepertiga wajah anterior bagian bawah menjadi lebih besar dari total keseluruhan tinggi wajah (dolichofacial). ${ }^{10,17,20}$

Panjang mandibula pada subjek OSNA memiliki nilai lebih besar daripada subjek normal, sudut gonial yang besar, posisi mandibula terletak lebih ke bawah dan memiliki sudut bidang oklusal yang curam. ${ }^{8}$ Pada penelitian ini tidak dapat terbukti secara statistik, walaupun terlihat perbedaan nilai rerata di antara kedua subjek, perbedaan nilai antara kedua subjek ini juga tidak sesuai dengan 
teori-teori sebelumnya sebab pada penelitian ini terlihat nilai rerata lebih besar ditemukan pada subjek normal daripada subjek OSNA dengan kebiasaan buruk napas mulut. Cheng, dkk melakukan penelitian mengenai efek yang disebabkan oleh OSNA pada subjek dengan rentang usia yang besar (3,8-25,8 tahun), disimpulkan bahwa semakin muda usia subjek, penyimpangan terhadap dentokraniofasial juga Farisith, Midredunt, Krowataty terlihat. ${ }^{8}$ Lagipula pertumbuhan mandibula justru mengalami percepatan saat masa pubertal hingga masa pertumbuhan berakhir. $^{3}$

Hubungan antara Tumbuh Kembang Mandibula dengan Postur Kepala pada Subjek OSNA dengan Kebiasaan Buruk Napas Mulut

Beberapa peneliti menyatakan bahwa postur kepala merupakan suatu kesatuan yang saling berhubungan antara OSNA, penyimpangan postur kepala dan penyimpangan morfologi dent okraniofasial, hal ini juga dinyatakan oleh Purwanegara, prevalensi subjek yang mengalami penyimpangan dentokraniofasial pada subjek OSNA dengan postur kepala menyimpang sebesar $55,3 \%$ dan tanpa postur kepala menyimpang sebesar $44,7 \% .^{9,11,19}$ Postur kepala yang menengadah sering dihubungkan dengan wajah anterior tinggi dan wajah posterior yang pendek, besarnya inklinasi mandibula, wajah yang retrognatism, mandibula ke arah bawah dan belakang serta kecilnya lebar antero-posterior kraniofasial dan kecilnya lebar dari rongga nasofaring. ${ }^{10-12,21,22}$

Dari ketiga variabel pengukuran tumbuh kembang mandibula pada penelitian ini, hanya variabel rotasi mandibula yang menunjukkan adanya korelasi antara tumbuh kembang mandibula pada subjek OSNA dengan kebiasaan buruk napas mulut dengan postur kepala. Seperti yang telah diuraikan di atas bahwa pertumbuhan mandibula masih terjadi hingga akhir masa pertumbuhan walaupun pertumbuhan maksila telah berhenti. ${ }^{3}$ Purwanegara juga menyatakan bahwa penyimpangan dentokranio fasial pada subjek OSNA dengan kebiasaan buruk napas melalui mulut juga lebih nyata terlihat dalam arah vertikal daripada arah antero-posterior maupun transversal. ${ }^{19}$

\section{Kesimpulan}

Perlu dilakukan penelitian lanjutan dengan sampel yang lebih besar, dengan pengelompok an subjek berdasarkan keparahan terjadinya obstruksi saluran napas atas, pengukuran terhadap anatomi rongga hidung, rentang usia yang lebih besar serta pengelompokan berdasarkan jenis kelamin atau dilakukan penelitian lanjutan bersifat longitudinal sehingga didapat hasil penelitian yang akurat. Hal terpenting lainnya adalah meningkatkan kualitas gambaran dari radiografi sefalometri sehingga terhindar dari kemungkinan terjadinya kesalahan dalam penapakan sefalometri. Diperlukan sosialisasi pada masyarakat dan kalangan medik melalui penyuluhan dan pertemuan ilmiah mengenai pentingnya deteksi dini terjadinya obstruksi saluran napas atas sebagai usaha pencegahan perawatan dentokraniofasial dan untuk tujuan melakukan rujukan ke bagian THT.

\section{Daftar Acuan}

1. Enlow DH dan Hans MG. Essential of Facial Growth.Chicago WB Saunders Co. hal.13, 1832, 122-145, 202-4

2. Bishara SE. Textbook of Orthodontics. Chicago WB. Saunders Company. 2001. Hal. 31-51.

3. Proffit WR, Fields HW. Contemporary Orthodontics. $3^{\text {rd }}$ ed. St Lois Mosby. 2000. Hal. 39-41, 48-9, 98-104, 113-42, 175-8, 180.

4. Moyers RE. Handbook of Orthodontics. $4^{\text {rd }} e d$. Year Book Medical Publishers. 1988. Hal. 5765, 206-7.

5. Glinka JSVD.Antropologi Ragawi. Surabaya.FGK Universitas Airlangga. 2001. Hal.1-10, 26-33.

6. Newman WA. Kamus Kedokteran Dorland/Dorland ed.29. EGC. Translation of Dorland's Illustrated Medical Dictionary ed.29 $9^{\text {th }}$ WB Saunders Co. 2000. Hal.1521.

7. Bailey BJ, Calhoun KH, et al. Head and Neck Surgery-Otolaryngology $3^{\text {rd }}$ ed. Vol.1. Lippincott Williams \& Wilkins. Hal.293, 299-301. 
8. Cheng MC, Enlow DH, Papsidero M, et.al. Developmental effects of impaired breathing in face of the growing child. Angle Orthod 1988;58; 309-18.

9. Vig PS, Showfety KJ, Phillips C. Experimental manipulation of head posture. Am J Orthod 1980; 77(3): 258-68.

10. Solow B, Siersbák-Nielsen S, Greve E. Airway adequacy, head posture, and craniofacial morphology. Am J Orthod 1984;86(3):214-23.

11. Solow B, Sandham A. Cranio-cervical posture : a factor in the development and function of the dentofacial structures. Eur Journ of Orthod 2002; 24(5):447-56

12. Solow B, Tallgren A. Head posture and craniofacial morphology. Am J Phys Anthropol 1976; 44 : 417-36.

13. Vig PS, Rink JF, Showfety KJ. Adaptation of head posture in response to relocating the center of mass: a pilot study. Am J Orthod 1983; 83(2): 138-42.

14. Major MP, Flores-Mir C, Major PW. Assessment of lateral cephalometric diagnosis of adenoid hypertrophy and posterior upper airway obstruction: A systematic review. Am J Orthod Dentof Orthop 2006;130 :700-6.

15. Warren DW, Hairfield WM, Seaton D, Morr KE. The relationship between nasal airway size and nasal-oral breathing. Am J Orthod Dentof Orthop 1988;93: 289-93.

16. Solow B, Tallgren A. Dentoalveolar morphology in relation to craniocervical posture. Angle Orthod 1977;47 :157-64.

17. Opdebeeck H, Bell WH, Eisenfeld, Mishelevich. Comparative study between the SFS and LFS rotation as a possible morphogenic mechanism. Am J Orthod 1978;74(5) :509-21.

18. Kerr WJS, McWilliam JS, Linder-Aronson S. Mandibular form and position related to changed mode of breathing - a five-year longitudinal study. Angle Orthod 1987;59(2) :91-6.

19. Purwanegara MK. Pengaruh Kebiasaan Buruk Bernapas Melalui Mulut pada Penderita Obstruksi Saluran Napas Atas terhadap Morfologi Dentokraniofasial. Disertasi. Universitas Indonesia, 2007.

20. Koski K, Lähdemäki P. Adaptation of the mandible in children with adenoids. Am J Orthod 1975;68(6) :660-5.

21. Mc.Namara JA, Brudon WL. Orthodontics and Dentofacial Orthopedics. Needham Press, Inc.2001. Hal.122-8.

22. Solow B, Siersbǽk-Nielsen S. Growth changes in head posture related to craniofacial development. Am J Orthod Dentofac Orthop 1986;89 :132-40. 